\title{
Multi-scale spatial variation in stable isotope and fatty acid profiles amongst temperate reef species: implications for design and interpretation of trophic studies
}

\author{
M. A. Guest ${ }^{1}$, A. J. Hirst ${ }^{1,2, *}$, P. D. Nichols ${ }^{3,4}$, S. D. Frusher ${ }^{1}$ \\ ${ }^{1}$ Tasmanian Aquaculture and Fisheries Institute, University of Tasmania, Hobart, Tasmania, Australia \\ ${ }^{2}$ Marine and Freshwater Fisheries Research Institute, Queenscliff, Victoria, Australia \\ ${ }^{3}$ CSIRO Marine and Atmospheric Research, Hobart, Tasmania, Australia \\ ${ }^{4}$ Antarctic and Climate Ecosystems, University of Tasmania, Hobart, Tasmania, Australia
}

\begin{abstract}
Stable isotopes of carbon and nitrogen and fatty acid analyses are increasingly being used in combination to determine the trophic structure of marine systems. For stable isotopes, the variability in carbon and nitrogen isotopic signatures has long been recognised and has been characterised for some taxa. Whilst it is known that metabolic processes may influence fatty acid profiles, the spatial variability of fatty acid profiles has not been documented. Understanding at what scale these 2 biochemical tracers vary, and if the scale of variability corresponds between tracers, is crucial for the correct design and interpretation of combined tracers in trophic studies. This study is the first to examine spatial variability in fatty acid profiles per se, and in combination with stable isotope ratios in the same organisms at multiple spatial scales. We used a spatially hierarchical design which sampled across broad geographic regions, reefs within regions, and also between different parts of macroalgal plants common on temperate reefs. For stable isotopes of carbon and nitrogen, variability was greatest at intermediate spatial scales (between locations within regions, and sites within locations). In contrast, fatty acid profiles showed the greatest variation amongst individual replicates of lobster, abalone and macroalgae. This study demonstrates that for the increasing number of trophic studies using combined biochemical tracers, sampling design should cater to the differences in the variability of each tracer technique and allocate sampling accordingly.
\end{abstract}

KEY WORDS: Stable isotopes · Fatty acid analysis $~$ Nested hierarchical design $\cdot$ Multivariate variance components · Tasmania

\section{INTRODUCTION}

Biochemical tracers such as stable isotopes of carbon and nitrogen, and more recently, fatty acid analyses, are widely used to examine the diet of consumers and the trophic structure of marine systems. The basis of these approaches is that a consumer incorporates the 'marker' or 'signature' of its food source into its somatic tissue with minimal or predictable changes (Corraze 1999, Peterson 1999). Variation in the ratio of the rare to heavy isotope is referred to as fractionation, and is due to differential discrimination of the rare to heavy isotope during chemical reactions associated with metabolic processes, and differential diffusion of isotopes during uptake (Peterson \& Fry 1987). As carbon changes very little between successive trophic levels (0-1\%, McCutchan et al. 2003), the carbon isotope can often indicate the ultimate source of primary production at the base of a consumer diet. The nitrogen isotope experiences greater fractionation per trophic level $(3-4 \%$ ) and is thus used to infer the trophic status of a consumer (McCutchan et al. 2003). Signature fatty 
acids include individual fatty acids that are rare, and unique ratios of commonly occurring fatty acids, both of which can be reflected in the fatty acid profile of a consumer (Dalsgaard et al. 2003). Variation in the fatty acid profiles of organisms is associated with the metabolic process of the organism (Dalsgaard et al. 2003).

Environmental factors have been identified as the primary mechanism influencing the fractionation rates (variability) of isotopic ratios. For example, light intensity (Hemminga \& Mateo 1996, Alcoverro et al. 2001), temperature (Hemminga \& Mateo 1996), $\mathrm{CO}_{2}$ availability (Burkhardt et al. 1999), water depth (Grice et al. 1996), and nutrient source (Marguillier et al. 1997, Waser et al. 1998, Finlay 2004) influence isotope ratios of autotrophs by altering the rate of productivity. Such factors differ across a range of spatial scales, potentially altering the isotopic ratio of the consumers that depend upon them. As variations in fatty acid profile are associated with the metabolic processes of an organism, factors that have the capacity to alter metabolic processes arguably have the capacity to influence the variation in fatty acid profiles of autotrophs and consumers. The extent to which fatty acids may be altered may also depend on the role of the fatty acid in the target organism metabolism (Chandrapavan et al. 2009). To date, the impact of these factors on fatty acid profiles has primarily been limited to laboratory or captive studies and can vary amongst species (Dalsgaard et al. 2003).

Examination of the spatial scale of tracer variation has only been conducted for stable isotopes. For example, kelp plants collected from across the Aleutian Island chain, Alaska (USA), were more variable in $\delta^{13} \mathrm{C}$ signatures between sites (i.e. separated by 100 s of metres and nested within islands) than islands (separated by $10 \mathrm{~s}$ of $\mathrm{km}$; Simenstad et al. 1993). Several other studies have also shown that carbon isotope ratios vary at a range of spatial scales (Boon \& Bunn 1994, Jennings et al. 1997, Boyce et al. 2001). Whilst this research is useful in highlighting the importance of quantifying the variance of stable isotope signatures at a range of scales, the lack of precise information about the scale investigated (either because it is not reported or is difficult to discern with any accuracy from figures) limits the utility of these results in guiding the design of experiments in contemporary trophic studies.

Typically, studies that aim to determine trophic structure of natural systems use surveys that sample a range of consumers and their potential food sources. Correlations between the tracer signature of a consumer and a potential food source provide an indication of likely dietary contributions, and reduce the potential complexity of dietary relationships which may then be verified more explicitly using experimental means. However, as many questions of trophic interest incorporate a range of spatial scales (e.g. inshore versus offshore movement of carbon, Odum et al. 1979, Deegan \& Garritt 1997; contribution of marine versus terrestrial carbon to coastal food webs, Andrews et al. 1998, Dittmar et al. 2001), high variability may obscure, and potentially confound, interpretation of trophic relationships where scales of variation are not sufficiently understood.

Fatty acids are increasingly the tracer of choice to complement the use of stable isotope analysis to clarify the trophic structure of marine systems (e.g. Kharlamenko et al. 2001, Alfaro et al. 2006, Guest et al. 2008, 2009, Jaschinski et al. 2008, Soreide et al. 2008, Stevens et al. 2008, Tucker et al. 2008, Jack et al. 2009). This is primarily due to the potentially greater resolving power of the combined approach in discriminating among food sources. However, no studies have examined the spatial variability of stable isotopes and fatty acids when combined to address trophic questions. Such studies are done with the implicit assumption that an experiment designed to suit one technique will also suit the other, despite no knowledge of the relative scales of variability in the biochemical tracer ratios of the target organisms. Moreover, there are no examples wherein the spatial variability of fatty acid profiles has been quantified despite their wide application. In part, this is because fatty acid dietary analysis involves quantifying the variance amongst many fatty acids simultaneously (often $>100$ fatty acid profiles), using multivariate statistical techniques such as discriminant function analysis (Phillips et al. 2003a) or classification trees (Iverson et al. 1997, 2007). However, statistical methods for partitioning variance among multivariate data are now available (McArdle \& Anderson 2001, Anderson et al. 2005). In this study we quantified spatial variance in fatty acid profiles within nestedhierarchical sampling designs using a nonparametic test, permutational multivariate analysis of variance (PERMANOVA; Anderson 2005).

Globally, temperate reef systems are dominated by structurally complex and diverse macroalgal assemblages (Steneck et al. 2002). Brown algae dominate these systems and provide habitat for a diversity of fish and invertebrates including several of major economic importance. In Tasmania, Australia, the sea urchin Heliocidaris erythrogramma, the purple wrasse Notolabrus fucicola, the southern rock lobster Jasus edwardsii and the black lip abalone Haliotis rubra are common residents of algal-dominated reefs, the latter 2 being important commercial fishery species. N. fucicola feeds on small crustaceans and molluscs (Denny \& Schiel 2001), whilst $J$. edwardsii is considered opportunistic, feeding on urchins, ascidians or abalones (Guest et al. 2009). H. rubra and H. erythrogramma are herbivorous grazers (Sanderson et al. 1996, Guest et al. 
2008). The dominant brown algal species in these systems include Ecklonia radiata (Laminariales) and Phyllospora comosa (Fucales), although Durvillaea potatorum (Durvillaeales) is also common in the upper sublittoral along exposed coastlines. Little is known about the contribution of these autotrophs to the dominant consumers in these systems, and biochemical tracer techniques are increasingly being considered as a means to resolve their trophic status in Tasmania and elsewhere (Guest et al. 2008).

Here we examined the spatial variability of stable isotope ratios of carbon and nitrogen, and the fatty acid profiles of brown algal, invertebrate (including rock lobster and abalone) and fish reef species at 3 spatial scales (between regions, between reefs within a region, and between parts of plants) that are commonly of interest in trophic studies. Specifically, we addressed: (1) at what spatial scales do stable isotope ratios and fatty acid profiles of target organisms vary, (2) does this level of variability correspond between tracers, and (3) what are the implications for the design and interpretation of trophic studies, particularly when comparing across larger spatial scales?

\section{MATERIALS AND METHODS}

Survey design and field methods. Subtidal marine primary producers (autotrophs) and consumers were sampled at 2 distinct spatial scales to assess the level of variance expressed at spatial scales relevant to the design, analysis and interpretation of diet studies. All samples were collected between June and late August (Austral winter) in cooler water temperatures and outside the peak growing season for the species examined. Samples were collected at (1) a broad regional scale encompassing the east, southeast and west coasts of Tasmania (reefs separated by 100s of $\mathrm{km}$ ), (2) a smaller (meso) scale (reefs separated by 100 to $1000 \mathrm{~m}$ ) and (3) between the parts of macroalgal plants. Ideally we would have included each of these scales within a single survey design; however, this would have been logistically impractical and beyond the resources of this study. We see the multi-scale approach as a reasonable compromise given these limitations.

Variation at regional and meso spatial scales was examined using a nested, spatially-hierarchical design. At the broad regional scale, 5 regions were selected that corresponded with biogeographic regions identified by Edgar et al. (1997) based on the faunal and floristic assemblage structure of subtidal reefs (Fig. 1). Within each region, 3 locations separated by a distance of approximately $1 \mathrm{~km}$ were selected, and fish, invertebrates and macroalgae were sampled for stable isotope and fatty acid analyses ( $\geq 3$ replicate individuals were

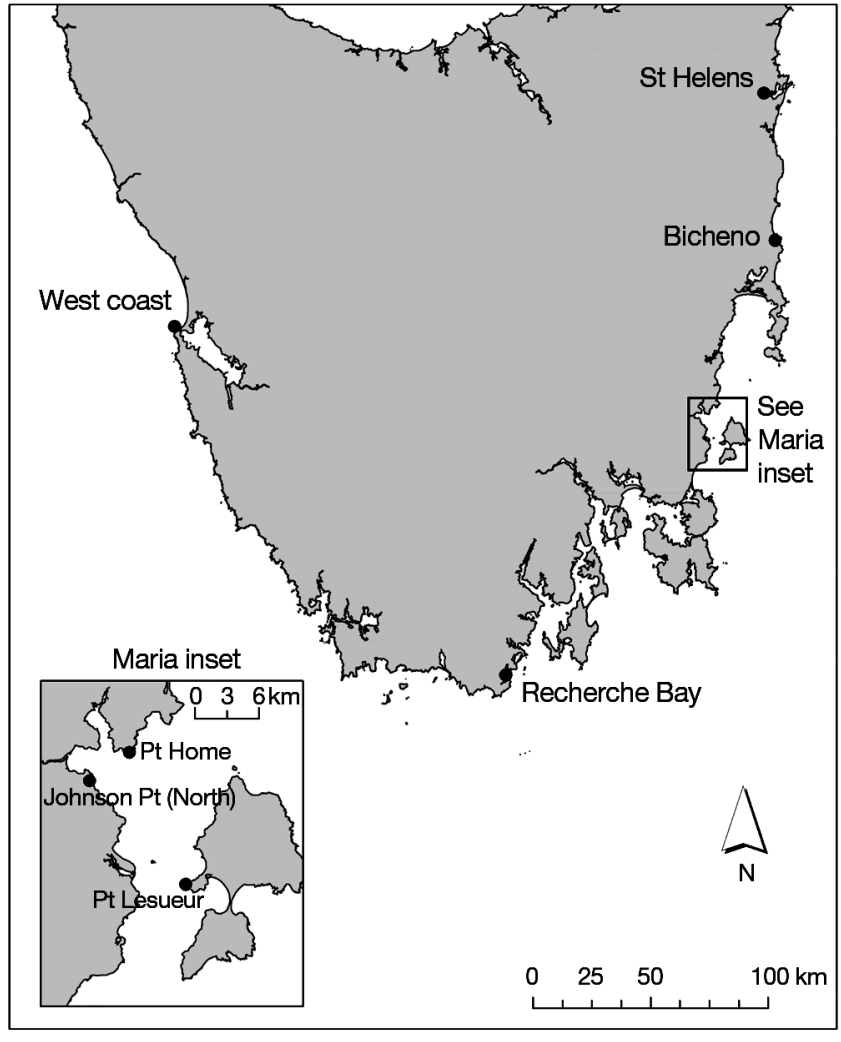

Fig. 1. Tasmania, showing 5 regions sampled: St. Helens, Bicheno, Maria Island, Recherche Bay and West Coast. The Maria Island inset shows the location of the 3 sites sampled during the meso-scale survey

collected where possible). At the meso-scale, 3 locations adjacent to Maria Island (Fig. 1), each separated by a distance of $1 \mathrm{~km}$, were selected at random, and within these locations, invertebrates and macroalgae were sampled at 3 sites each separated by $100 \mathrm{~m}$. The sizes of individuals within a species were similar. The mean size of Jasus edwardsii was $99.56( \pm 1.32 \mathrm{SE}) \mathrm{mm}$ carapace length; Haliotis rubra, $102.85( \pm 2.94) \mathrm{mm}$ shell width; and Notolabrus fucicola $231( \pm 3.41) \mathrm{mm}$ fork length. There was no relationship between the size of a species and tracer signatures (analyses not shown, but see Guest et al. 2009 for J. edwardsii), so individuals within a species from all size classes were pooled for all analyses.

The final spatial scale examined differences in stable isotope signatures between different parts of 3 brown macroalgal species common on Tasmanian subtidal reefs. Replicate algal samples were collected at random at a single location, and then sections of tissue were collected from designated parts of the algae (e.g. stipe, frond and apex). For Ecklonia radiata, the distal parts of the alga such as the apex, upper frond, lower frond and stipe were collected, and additional samples 
were taken from the central blade of the alga. For Durvillaea potatorum, the same distal regions were sampled but the midstem was taken at a point midway along the length of the central frond. Parts of Phyllospora comosa sampled were the frond, bladder and stipe. With the exception of the lobster Jasus edwardsii, abalone Haliotis rubra and kelp E. radiata, analyses incorporating all species across all locations were not possible due to natural limits to species ranges and/or the absence of species at all sites visited (Table 1).

All samples were frozen after collection, then thawed and rinsed in distilled water prior to processing. Leg muscle from the second or third walking leg of lobsters was removed from the exoskeleton, and a $2 \mathrm{~cm}^{3}$ section of muscle was removed from the fish and from the abalone foot for later analysis. All samples were then freeze-dried for 24 to $48 \mathrm{~h}$ and ground using a mortar and pestle. Samples were then partitioned for fatty acid and stable isotope analyses.

Chemical analyses. The ratios of ${ }^{13} \mathrm{C} /{ }^{12} \mathrm{C}$ and ${ }^{15} \mathrm{~N} /{ }^{14} \mathrm{~N}$ for all samples were calculated as the relative per mille (\%) difference between the sample and the recognised international standard (Pee Dee belemnite carbonate for carbon; air for nitrogen) and analysed on a Micromass Isochrom continuous flow isotope ratio mass spectrometer. Precision of the mass spectrometer calculated from duplicate samples was $0.2 \%$.

Dried animal and algal samples (15 mg of each) were trans-methylated to produce fatty acid methyl esters (FAME) using methanol:chloroform:concentrated hydrochloric acid $\left(10: 1: 1,80^{\circ} \mathrm{C}, 2 \mathrm{~h}\right)$. Direct trans-methylation of samples has previously been validated against conventional methods (Christie 1982) for a microheterotroph

Table 1. Species analysed at each of 3 spatial scales: regional, meso and intra-plant for stable isotope (SI) and fatty acid (FA) chemical tracers. $n$ : number of replicates

\begin{tabular}{|lccc|}
\hline Scale/species & $\mathrm{n}$ & $\mathrm{SI}$ & $\mathrm{FA}$ \\
\hline Regional & & & \\
Jasus edwardsii (lobster) $_{\text {Haliotis rubra (abalone) }}$ & 3 & $\mathrm{x}$ & $\mathrm{x}$ \\
Ecklonia radiata (brown alga) $_{\text {Notolabrus fucicola (wrasse) }}^{\mathrm{a}}$ & 3 & $\mathrm{x}$ & $\mathrm{x}$ \\
Phyllospora comosa (brown alga) $^{\text {Meso }}$ & 3 & $\mathrm{x}$ & $\mathrm{x}$ \\
J. edwardsii & 3 & & $\mathrm{x}$ \\
H. rubra & & & \\
E. radiata & 3 & $\mathrm{x}$ & $\mathrm{x}$ \\
Heliocidaris erythrogramma (urchin) & 3 & $\mathrm{x}$ & \\
Intra-plant & 3 & $\mathrm{x}$ & $\mathrm{x}$ \\
Durvillaea potatorum (brown alga) & 5 & $\mathrm{x}$ & \\
E. radiata & 9 & $\mathrm{x}$ & \\
P. comosa & 9 & $\mathrm{x}$ & \\
${ }^{\mathrm{a} C o l l e c t e d ~ u s i n g ~ b a i t e d ~ f i s h ~ t r a p s ~}$ & & & \\
\hline
\end{tabular}

(Lewis et al. 2000) and for striped trumpeter larvae and rotifers (M. Bransden \& G. Dunstan unpubl. data). FAME were extracted into hexane-chloroform $(4: 1,3 \times 1.5 \mathrm{ml})$. Gas chromatographic (GC) analyses were performed with an Agilent Technologies 6890N GC equipped with an HP-5 capillary column (50 $\mathrm{m} \times 0.32 \mathrm{~mm}$ i.d.), a flame ionisation dector (FID), a split/splitless injector and an Agilent Technologies 7683 auto sampler, using GC operating conditions previously described (Phillips et al. 2003b). Individual components were identified using mass spectral data (Finnigan Thermoquest GCQ GCmass spectrometer) and by comparing retention time data with those obtained for authentic and laboratory standards.

Data analysis. Stable isotope signatures and fatty acid profiles at the regional- and meso-scale were analysed using a 2-way nested design in which variance was partitioned into region, location and site components using univariate and recently developed multivariate (PERMANOVA; Anderson 2005) statistical tests. All factors were treated as random. The objective was to identify the spatial scales at which chemical dietary markers varied and link these patterns to diet-related questions addressed at a number of different spatial scales (i.e. broad regional, intermediate and within producers). Variance components for stable isotope signatures of $\delta^{13} \mathrm{C}$ and $\delta^{15} \mathrm{~N}$ were calculated using restricted maximum likelihood (REML) estimation (linear mixed-effects model, SYSTAT 12). The residual variance (error term) component in this design relays the unexplained variation expressed principally between replicate samples. Variance components for each of the model terms were expressed as a percentage of the total variance. As there was no correlation between the size of lobster and abalone and $\delta^{13} \mathrm{C}$ and $\delta^{15} \mathrm{~N}$ stable isotope ratios, irrespective of the spatial scale examined, size was not included as a covariate in these analyses.

Fatty acid profiles (comprising 107 individual fatty acids) were analysed using nested 2-way PERMANOVA (Anderson 2005) based on Euclidean distances between samples. PERMANOVA is a multivariate statistical routine for testing the simultaneous response of 1 or more variables within an analysis of variance (ANOVA) experimental design on the basis of any distance measure, using permutation methods (Anderson 2005). A triangular matrix summarising similarity in fatty acid profiles between samples in multi-dimensional space was generated using a Euclidean distance measure on the untransformed percent composition of all 107 fatty acids. Variance components for each of the terms were calculated by equating the PERMANOVA mean squares to their expected values using a multivariate analogue of the ANOVA approach (Searle et al. 1992, Anderson et al. 
2005). The statistical significance of each term was tested using unrestricted permutations of the raw data ( $\mathrm{n}=999$ permutations; Anderson 2005).

Differences in $\delta^{13} \mathrm{C}$ and $\delta^{15} \mathrm{~N}$ stable isotope signatures between parts of 3 macroalgal species were analysed using a randomised block ANOVA design in which differences between plant parts were treated as a fixed factor and replicate algae as a blocking factor. This design allowed us to adjust for high variability in stable isotope signatures between individual algal plants (see 'Results') whilst comparing plant parts. Where treatment effects were detected, algal parts were contrasted using Tukey's HSD post hoc tests.

\section{RESULTS}

\section{Broad regional scale}

The greatest proportion of variance was expressed at the location, followed by the residual (i.e. between replicate samples) spatial scale (Table 2, Figs. 2 \& 3). Regional differences by comparison were minor (i.e. many variance components were 0 ) and the $\delta^{13} \mathrm{C}$ signature of Ecklonia radiata was the only isotope signature that varied substantially at the regional scale.

The $\delta^{13} \mathrm{C}$ signatures of all species across regional and locational scales were wide but greatest for Haliotis

Table 2. Restricted maximum likelihood variance components estimates for $\delta^{13} \mathrm{C}$ and $\delta^{15} \mathrm{~N}$ signatures of Jasus edwardsii (lobster), Haliotis rubra (abalone), Ecklonia radiata (brown alga) and Notolabrus fucicola (wrasse) individuals sampled from different regions and locations (loc) nested within regions, displaying percentage of the total variance for each term. Var. $=$ variance, comp. $=$ component

\begin{tabular}{|c|c|c|c|c|c|}
\hline \multirow{2}{*}{ Source } & \multirow[t]{2}{*}{ df } & \multicolumn{2}{|c|}{$-\delta^{13} \mathrm{C}-$} & \multicolumn{2}{|c|}{$-\delta^{15} \mathrm{~N}-$} \\
\hline & & $\begin{array}{l}\text { Var. } \\
\text { comp. }\end{array}$ & $\begin{array}{c}\% \\
\text { var. }\end{array}$ & $\begin{array}{l}\text { Var. } \\
\text { comp. }\end{array}$ & $\begin{array}{c}\% \\
\text { var. }\end{array}$ \\
\hline \multicolumn{6}{|l|}{ J. edwardsii } \\
\hline Region & 4 & 0.124 & 6.0 & 0 & 0 \\
\hline Loc(Region) & 9 & 1.279 & 62.3 & 0.824 & 23.9 \\
\hline Residual & 28 & 0.651 & 31.7 & 2.619 & 76.1 \\
\hline \multicolumn{6}{|l|}{ H. rubra } \\
\hline Region & 4 & 0 & 0 & 0 & 0 \\
\hline Loc(Region) & 9 & 6.733 & 85.2 & 0.259 & 69.4 \\
\hline Residual & 28 & 1.169 & 14.8 & 0.114 & 30.6 \\
\hline \multicolumn{6}{|c|}{ E. radiata (excluding Bicheno) } \\
\hline Region & 3 & 1.839 & 29.2 & 0 & 0 \\
\hline Loc(Region) & 8 & 3.264 & 51.9 & 0.993 & 74.4 \\
\hline Residual & 24 & 1.189 & 18.9 & 0.342 & 25.6 \\
\hline \multicolumn{6}{|c|}{ N. fuciola (only Maria, Recherche and W. coast) } \\
\hline Region & 2 & 0 & 0 & 0 & 0 \\
\hline Loc(Region) & 6 & 0.374 & 38.2 & 2.112 & 35.6 \\
\hline Residual & 18 & 0.605 & 61.8 & 3.828 & 64.4 \\
\hline
\end{tabular}

Table 3. Nested 2-factor permutational multivariate analysis of variance (PERMANOVA) based on Euclidean distance matrix of fatty acid profiles for Jasus edwardsii (lobster), Haliotis rubra (abalone) and Ecklonia radiata and Phyllospora comosa (brown algae) individuals sampled from different regions and locations (loc) nested within regions. Shown are the pseudo-estimated variance components and the percentage variance for each term

\begin{tabular}{|c|c|c|c|c|c|c|}
\hline Source & df & MS & $F$ & $\mathrm{p}$ & Pseudo $\sigma$ & $\%$ \\
\hline \multicolumn{7}{|l|}{ J. edwardsii } \\
\hline Region & 4 & 65.751 & 2.496 & 0.012 & 4.38 & 19.7 \\
\hline Loc(Region) & 10 & 26.348 & 1.934 & 0.008 & 4.24 & 19.1 \\
\hline Residual & 30 & 13.624 & & & 13.62 & 61.3 \\
\hline \multicolumn{7}{|l|}{ H. rubra } \\
\hline Region & 4 & 40.309 & 1.342 & 0.074 & 1.14 & 5.2 \\
\hline Loc(Region) & 10 & 30.046 & 1.860 & 0.001 & 4.63 & 21.1 \\
\hline Residual & 30 & 16.156 & & & 16.16 & 73.7 \\
\hline \multicolumn{7}{|l|}{ E. radiata } \\
\hline Region & 4 & 112.774 & 2.084 & 0.033 & 6.52 & 19.7 \\
\hline Loc(Region) & 10 & 54.103 & 4.196 & 0.001 & 13.74 & 41.4 \\
\hline Residual & 30 & 12.893 & & & 12.89 & 38.9 \\
\hline \multicolumn{7}{|c|}{ P. comosa (excluding West Coast) } \\
\hline Region & 3 & 158.121 & 3.881 & 0.026 & 13.04 & 38.0 \\
\hline Loc(Region) & 8 & 40.739 & 3.538 & 0.001 & 9.74 & 28.4 \\
\hline Residual & 24 & 11.515 & & & 11.52 & 33.6 \\
\hline
\end{tabular}

rubra, ranging from -24.3 to $-12.6 \%$ (mean $\pm \mathrm{SE}=$ $-18.6 \pm 0.4 \%$ ), followed by Ecklonia radiata ( -24.4 to $-14.9 \%$, mean $=-18.5 \pm 0.5 \%$ ), Jasus edwardsii $(-20.2$ to $-13.5 \%$, mean $=-15.6 \pm 0.2 \%$ ), and Notolabrus fucicola $(-19.0$ to $-14.3 \%$, mean $=-16.0 \pm 0.2 \%$ ). The range of $\delta^{15} \mathrm{~N}$ signatures was greatest for $N$. fucicola (16.9 to $7.9 \%$, mean $=14.5 \pm 0.2 \%$, followed by $H$. rubra (16.1 to $7.3 \%$, mean $=8.9 \pm 0.3 \%$ ), J. edwardsii $(16.2$ to $7.9 \%$, mean $=13.9 \pm 0.2 \%$ ) , and E. radiata $(9.9$ to $5.3 \%$, mean $=7.7 \pm 0.4 \%$ o) .

By comparison, multivariate variance components of fatty acid profiles for Jasus edwardsii and Haliotis rubra were greatest at the residual scale (i.e. 61 and $74 \%$ of the total variance for $J$. edwardsii and H. rubra, respectively; Table 3). Similar amounts of variance were expressed at the location, residual, and to a lesser extent regional levels for the algae Ecklonia radiata and Phyllospora comosa, whereas variation was greatest between replicate samples for $J$. edwardsii and $H$. rubra.

The fatty acids $16: 0(8.7-22.3 \%$ of total), $20: 4 \omega 6$ $(10.6-18.7 \%)$ and $20: 5 \omega 3(4.6-14.0 \%)$ commonly occurred in all species (Table 4). For Jasus edwardsii, $18: 1 \omega 9 \mathrm{c}(16.1 \pm 2.5 \%)$ was the most abundant, with relatively high levels of $22: 6 \omega 3(8.5 \pm 2.0 \%), 18: 0$ (6.6 \pm $0.8 \%)$ and $16: 1 \omega 7 \mathrm{c}(4.0 \pm 0.5 \%)$. Haliotis rubra was

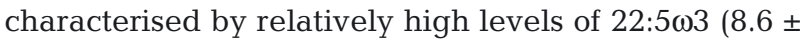
$0.2 \%)$, which was low or absent in all other species. $14: 0(4.7-7.5 \%), 18: 1 \omega 9 \mathrm{c}(17.7-21.5 \%)$ and $18: 4 \omega 3$ (4.6-5.4\%) were common in both brown algal species. 

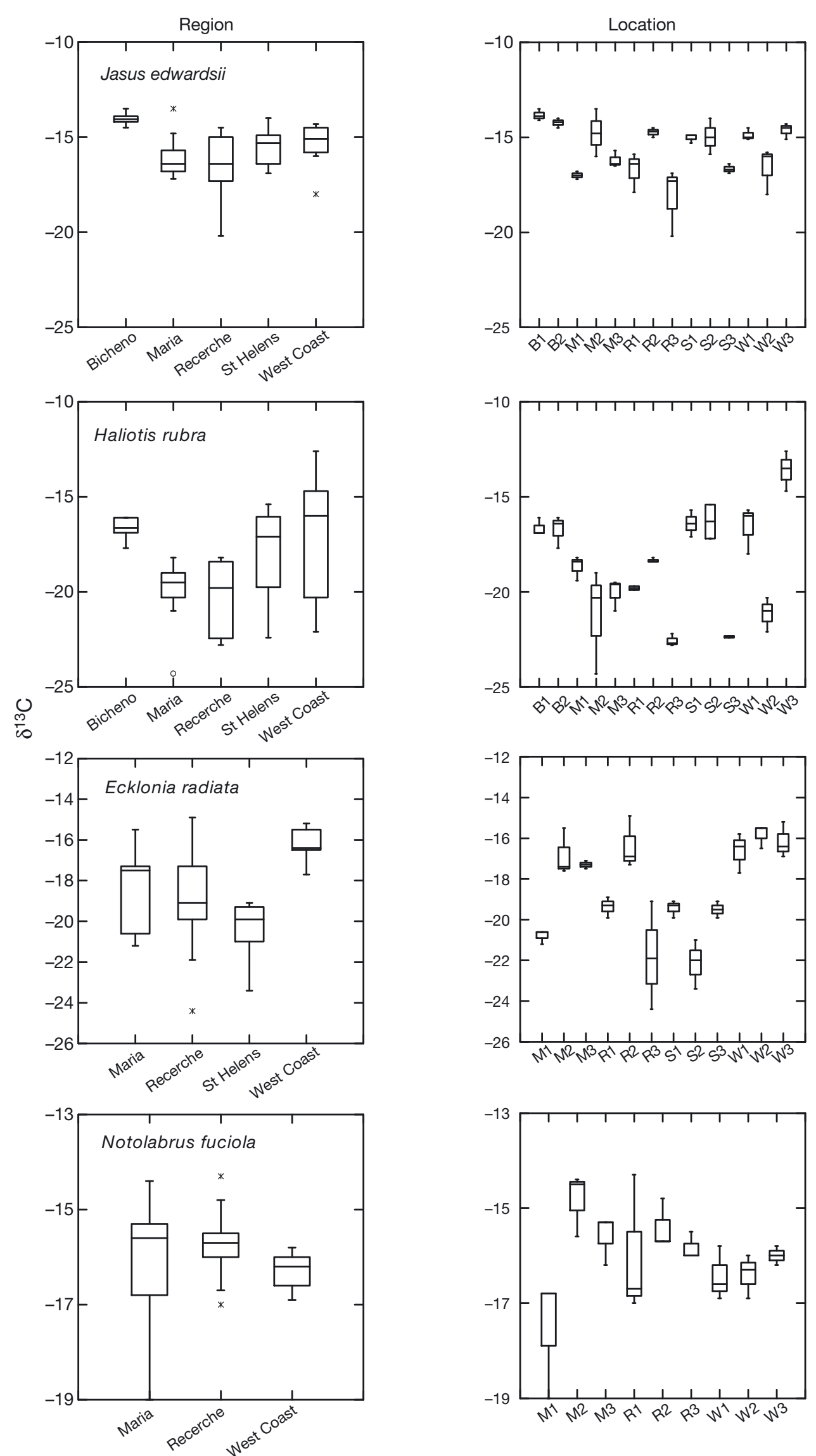

Fig. 2. $\delta^{13} \mathrm{C}$ ratios, displaying variance at regional and location (nested within region) spatial scales for Jasus edwardsii (lobster), Haliotis rubra (abalone), Ecklonia radiata (brown alga) and Notolabrus fucicola (wrasse). Horizontal lines are medians, boxes are inter-quartile ranges, and vertical bars are ranges excluding outliers $(*=$ outlier, $\circ=$ far outlier $)$ 
Guest et al.: Spatial variation of biochemical tracers

31
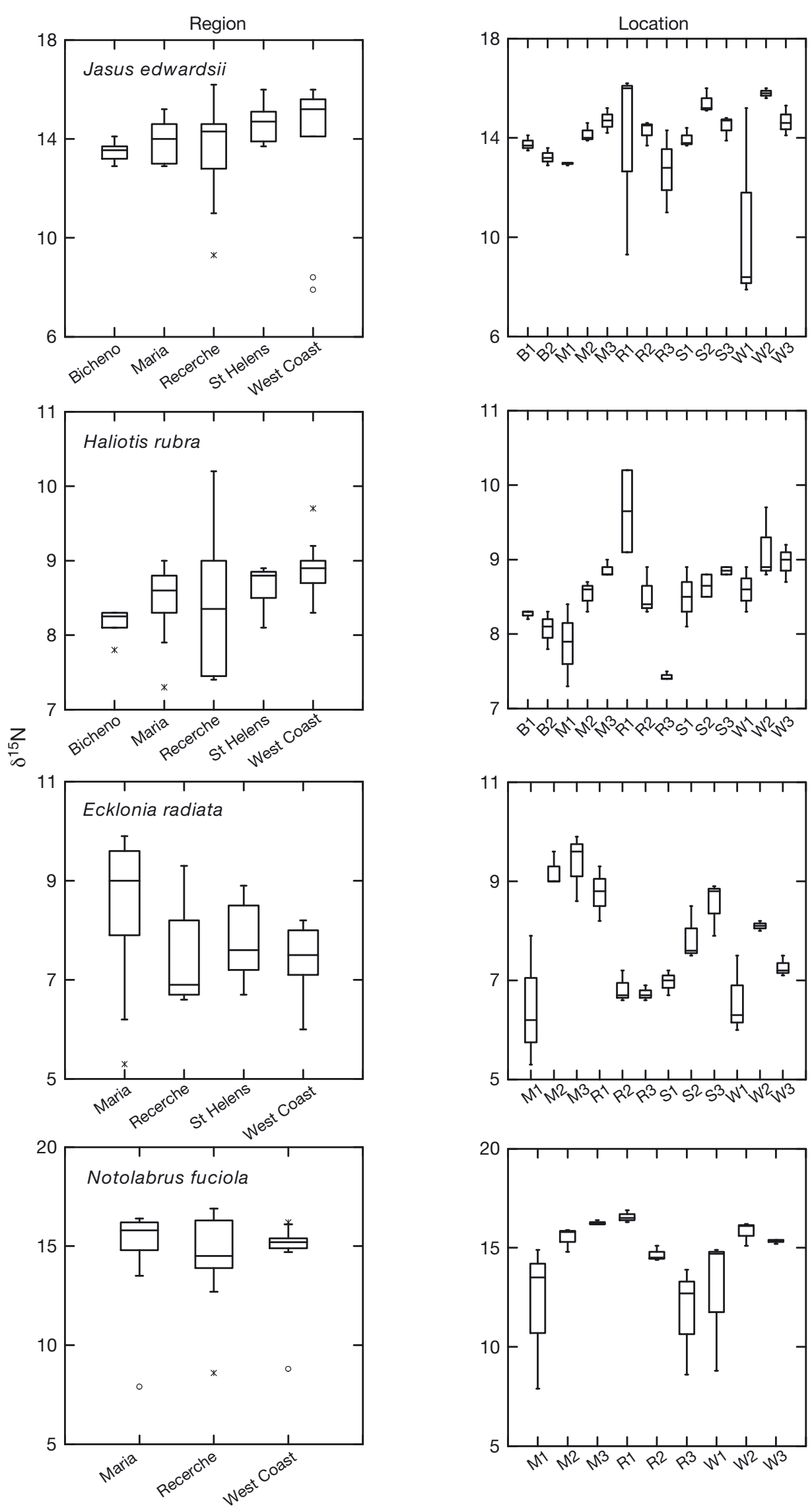

Fig. 3. $\delta^{15} \mathrm{~N}$ ratios. Other details as in Fig. 2 
Table 4. Mean percentage of most common fatty acids ( \pm SE) of Jasus edwardsii, Notolabrus fucicola, Haliotis rubra, Heliocidaris erythrogramma, Ecklonia radiata, and Phyllospora comosa. n: sample size, SFA: saturated fatty acids, MUFA: monounsaturated fatty acids, PUFA: polyunsaturated fatty acids, DHA: docosahexaenoic acid, DPA: docosapentaenoic acid

\begin{tabular}{|c|c|c|c|c|c|c|}
\hline Fatty acids & $\begin{array}{c}\text { Jasus } \\
\text { edwardsii } \\
\mathrm{n}=45\end{array}$ & $\begin{array}{c}\text { Notolabrus } \\
\text { fucicola } \\
\mathrm{n}=35\end{array}$ & $\begin{array}{l}\text { Haliotis } \\
\text { rubra } \\
\mathrm{n}=45\end{array}$ & $\begin{array}{c}\text { Heliocidaris } \\
\text { erythrogramma } \\
\mathrm{n}=36\end{array}$ & $\begin{array}{c}\text { Ecklonia } \\
\text { radiata } \\
\mathrm{n}=45\end{array}$ & $\begin{array}{c}\text { Phyllospora } \\
\text { comosa } \\
\mathrm{n}=36\end{array}$ \\
\hline $14: 0$ & $1.0 \pm 0.4$ & $2.2 \pm 0.2$ & $1.9 \pm 0.1$ & $3.3 \pm 0.2$ & $7.5 \pm 0.2$ & $4.7 \pm 0.2$ \\
\hline i15:0 & $0.1 \pm 0.0$ & $0.1 \pm 0.0$ & $0.1 \pm 0.0$ & $0.0 \pm 0.0$ & $0.0 \pm 0.0$ & $0.0 \pm 0.0$ \\
\hline 15:0 & $0.6 \pm 0.1$ & $0.4 \pm 0.0$ & $0.8 \pm 0.0$ & $0.1 \pm 0.0$ & $1.0 \pm 0.0$ & $0.5 \pm 0.0$ \\
\hline $16: 0$ & $12.4 \pm 0.9$ & $20.0 \pm 0.3$ & $19.6 \pm 0.2$ & $8.7 \pm 0.2$ & $22.3 \pm 0.3$ & $21.7 \pm 0.4$ \\
\hline $17: 0$ & $1.1 \pm 0.1$ & $0.8 \pm 0.0$ & $1.6 \pm 0.0$ & $0.1 \pm 0.0$ & $0.3 \pm 0.0$ & $0.4 \pm 0.1$ \\
\hline $18: 0$ & $6.6 \pm 0.8$ & $6.9 \pm 0.2$ & $6.1 \pm 0.1$ & $5.1 \pm 0.1$ & $1.1 \pm 0.1$ & $0.9 \pm 0.1$ \\
\hline $20: 0$ & $0.7 \pm 0.1$ & $0.2 \pm 0.0$ & $0.5 \pm 0.0$ & $0.5 \pm 0.0$ & $1.5 \pm 0.1$ & $0.6 \pm 0.0$ \\
\hline $21: 0$ & $0.2 \pm 0.1$ & $0.0 \pm 0.0$ & $0.0 \pm 0.0$ & $0.0 \pm 0.0$ & $0.1 \pm 0.0$ & $0.3 \pm 0.0$ \\
\hline $22: 0$ & $0.7 \pm 0.3$ & $0.1 \pm 0.0$ & $0.2 \pm 0.0$ & $0.0 \pm 0.0$ & $0.0 \pm 0.0$ & $0.3 \pm 0.0$ \\
\hline Sum SFA & $23.5 \pm 2.7$ & $30.7 \pm 0.7$ & $31.0 \pm 0.5$ & $17.8 \pm 0.5$ & $33.7 \pm 0.7$ & $29.5 \pm 0.9$ \\
\hline $16: 1 \omega 7 \mathrm{c}$ & $4.0 \pm 0.5$ & $2.1 \pm 0.2$ & $1.4 \pm 0.1$ & $0.2 \pm 0.0$ & $7.6 \pm 0.3$ & $4.8 \pm 0.1$ \\
\hline $16: 1 \omega 5 c$ & $0.1 \pm 0.1$ & $0.2 \pm 0.0$ & $0.3 \pm 0.1$ & $1.5 \pm 0.1$ & $0.5 \pm 0.0$ & $0.6 \pm 0.1$ \\
\hline $18: 1 \omega 9 \mathrm{c}$ & $16.1 \pm 2.5$ & $9.8 \pm 0.5$ & $7.2 \pm 0.2$ & $1.6 \pm 0.0$ & $21.5 \pm 0.2$ & $17.7 \pm 0.2$ \\
\hline $18: 1 \omega 7 \mathrm{C}$ & $3.4 \pm 0.4$ & $3.1 \pm 0.1$ & $7.4 \pm 0.1$ & $3.7 \pm 0.1$ & $0.5 \pm 0.1$ & $0.2 \pm 0.0$ \\
\hline $20: 1 \omega 7,9,11 \mathrm{c}$ & $2.5 \pm 2.1$ & $1.6 \pm 0.3$ & $3.0 \pm 0.1$ & $13.8 \pm 1.1$ & $1.2 \pm 0.2$ & $0.9 \pm 0.2$ \\
\hline $22: 1 \omega 7,9,11,13 c$ & $0.4 \pm 0.2$ & $0.6 \pm 0.1$ & $0.8 \pm 0.0$ & $4.8 \pm 0.2$ & $0.1 \pm 0.0$ & $0.2 \pm 0.0$ \\
\hline 24:1a and b & $0.0 \pm 0.0$ & $0.9 \pm 0.1$ & $0.1 \pm 0.0$ & $2.3 \pm 0.2$ & $0.1 \pm 0.0$ & $0.0 \pm 0.0$ \\
\hline Sum MUFA & $26.5 \pm 5.7$ & $18.3 \pm 1.2$ & $20.1 \pm 0.7$ & $28.0 \pm 1.7$ & $31.6 \pm 0.8$ & $24.3 \pm 0.6$ \\
\hline $18: 4 \omega 3$ & $0.5 \pm 0.1$ & $0.6 \pm 0.1$ & $0.5 \pm 0.0$ & $0.1 \pm 0.0$ & $5.4 \pm 0.4$ & $4.6 \pm 0.3$ \\
\hline $18: 2 \omega 6$ & $1.2 \pm 0.2$ & $1.4 \pm 0.1$ & $1.1 \pm 0.0$ & $0.1 \pm 0.0$ & $3.3 \pm 0.1$ & $6.1 \pm 0.2$ \\
\hline $20: 4 \omega 6$ & $11.0 \pm 1.3$ & $10.6 \pm 0.6$ & $12.1 \pm 0.2$ & $18.6 \pm 0.4$ & $14.9 \pm 0.4$ & $18.7 \pm 0.5$ \\
\hline $20: 5 \omega 3$ & $14.0 \pm 2.0$ & $7.4 \pm 0.2$ & $5.8 \pm 0.3$ & $9.8 \pm 0.2$ & $4.6 \pm 0.2$ & $5.7 \pm 0.3$ \\
\hline 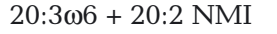 & $0.6 \pm 0.2$ & $0.5 \pm 0.0$ & $0.5 \pm 0.0$ & $11.9 \pm 0.2$ & $0.7 \pm 0.0$ & $1.6 \pm 0.1$ \\
\hline $20: 2 \omega 6$ & $1.2 \pm 0.2$ & $0.5 \pm 0.0$ & $0.1 \pm 0.0$ & $1.6 \pm 0.1$ & $0.0 \pm 0.0$ & $0.7 \pm 0.1$ \\
\hline 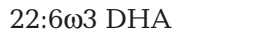 & $8.5 \pm 2.0$ & $19.2 \pm 1.1$ & $0.6 \pm 0.2$ & $0.0 \pm 0.0$ & $0.0 \pm 0.0$ & $0.2 \pm 0.0$ \\
\hline $22: 4 \omega 6$ & $1.6 \pm 0.5$ & $1.4 \pm 0.2$ & $2.7 \pm 0.1$ & $0.0 \pm 0.0$ & $0.0 \pm 0.0$ & $0.4 \pm 0.0$ \\
\hline 22:5ஸ3 DPA(3) & $2.0 \pm 0.5$ & $3.6 \pm 0.2$ & $8.6 \pm 0.2$ & $0.0 \pm 0.0$ & $0.0 \pm 0.0$ & $0.1 \pm 0.0$ \\
\hline $22: 3 \omega 6$ & $0.2 \pm 0.1$ & $0.2 \pm 0.0$ & $0.3 \pm 0.0$ & $0.0 \pm 0.0$ & $0.0 \pm 0.0$ & $0.1 \pm 0.0$ \\
\hline 22:2NMI+C22PUFA & $0.3 \pm 0.1$ & $0.6 \pm 0.1$ & $4.3 \pm 0.1$ & $0.4 \pm 0.0$ & $0.0 \pm 0.0$ & $0.0 \pm 0.0$ \\
\hline 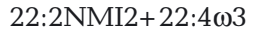 & $0.2 \pm 0.1$ & $0.2 \pm 0.0$ & $0.1 \pm 0.0$ & $0.7 \pm 0.0$ & $0.0 \pm 0.0$ & $0.1 \pm 0.0$ \\
\hline Sum PUFA & $41.3 \pm 7.3$ & $46.3 \pm 2.5$ & $36.5 \pm 1.3$ & $43.0 \pm 1.0$ & $28.8 \pm 1.1$ & $38.2 \pm 1.5$ \\
\hline Sum other $>1 \%^{a}$ & $4.2 \pm 1.0$ & $0.9 \pm 0.0$ & $8.2 \pm 0.3$ & $6.6 \pm 0.2$ & $0.0 \pm 0.0$ & $3.3 \pm 0.2$ \\
\hline Sum other $<1 \%{ }^{b}$ & $4.6 \pm 1.6$ & $3.8 \pm 0.3$ & $4.3 \pm 0.3$ & $4.5 \pm 0.4$ & $5.9 \pm 0.6$ & $4.7 \pm 0.6$ \\
\hline \multicolumn{7}{|c|}{ 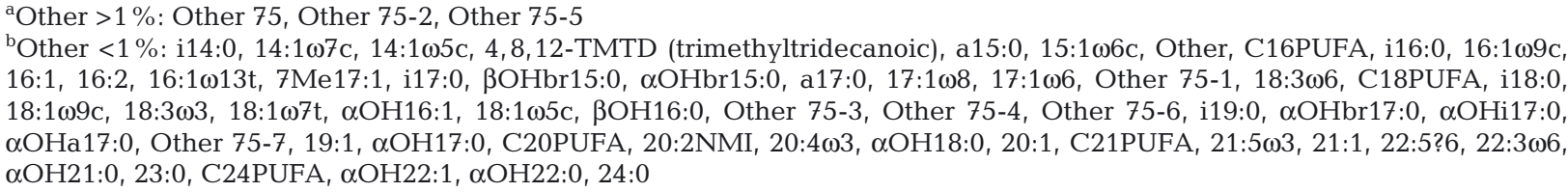 } \\
\hline
\end{tabular}

\section{Meso-scale (Maria Island)}

The greatest variation in stable isotope signatures was again found at smaller spatial scales (i.e. the nested spatial and residual terms; Table 5, Figs. 4 \& 5). The only exception to this pattern was recorded for the $\delta^{13} \mathrm{C}$ signature of Haliotis rubra, which displayed considerable variation between locations (Fig. 5), in turn reducing the relative amount of variance expressed at the site level.

The range of $\delta^{13} \mathrm{C}$ signatures of all species across meso- and site scales was greatest for the urchin Helio- cidaris erythrogramma $(-20.7$ to $-13.6 \%$, mean $=$ $-16.6 \pm 0.3 \%$ ), followed by Haliotis rubra ( -24.3 to $-16.2 \%$, mean $=-20.1 \pm 0.4 \%$, Ecklonia radiata $(-21.2$ to $-15.5 \%$, mean $=-18.1 \pm 0.3 \%$ ) and Jasus edwardsii $(-17.9$ to $-13.5 \%$, mean $=-16.6 \pm 0.2 \%)$. The range of $\delta^{15} \mathrm{~N}$ signatures was also greatest for $H$. erythrogramma ( 14.7 to $7.9 \%$, mean $=11.2 \pm 0.3 \%$ ), with the range of $\delta^{15} \mathrm{~N}$ signatures across meso- and site scales similar for $J$. edwardsii (15.7 to $9.3 \%$, mean $=14.1 \pm$ $0.2 \%$ ) followed by E. radiata $(10.7$ to $5.3 \%$, mean = $8.8 \pm 0.3 \%$ o $)$ and lastly, $H$. rubra $(10.4$ to $7.3 \%$, mean $=$ $9.0 \pm 0.4 \%$ o) 
The pattern for the fatty acid profiles was also similar to that found at the regional scale, with the greatest proportion of variance explained by the residual term (Table 6), indicating high variation between samples. In the case of Jasus edwardsii, this is likely to be because location and site did not vary significantly $(p>$

Table 5. Restricted maximum likelihood variance component estimates for $\delta^{13} \mathrm{C}$ and $\delta^{15} \mathrm{~N}$ signatures of Jasus edwardsii (lobster), Haliotis rubra (abalone) and Heliocidaris erythrogramma (sea urchin) individuals sampled from different locations within the Maria Island region and sites nested within locations displaying percentage of the total variance for each term. Var. $=$ variance, comp. $=$ component

\begin{tabular}{|c|c|c|c|c|c|}
\hline \multirow{2}{*}{ Source } & \multirow{2}{*}{$\mathrm{df}$} & \multicolumn{2}{|c|}{$-\delta^{13} \mathrm{C}-$} & \multicolumn{2}{|c|}{$-\delta^{15} \mathrm{~N}$} \\
\hline & & $\begin{array}{l}\text { Var. } \\
\text { comp. }\end{array}$ & $\begin{array}{c}\% \\
\text { var. }\end{array}$ & $\begin{array}{l}\text { Var. } \\
\text { comp. }\end{array}$ & $\begin{array}{c}\% \\
\text { var. }\end{array}$ \\
\hline \multicolumn{6}{|l|}{ J. edwardsii } \\
\hline Location & 2 & 0 & 0 & 0 & 0 \\
\hline Site(Location) & 6 & 0.470 & 48.2 & 0.275 & 12.2 \\
\hline Residual & 18 & 0.506 & 51.8 & 1.974 & 87.8 \\
\hline \multicolumn{6}{|l|}{ H. rubra } \\
\hline Location & 2 & 2.113 & 47.1 & 0.024 & 0.8 \\
\hline Site(Location) & 6 & 0.699 & 15.6 & 1.573 & 50.7 \\
\hline Residual & 18 & 1.678 & 37.4 & 1.503 & 48.5 \\
\hline \multicolumn{6}{|l|}{ E. radiata } \\
\hline Location & 2 & 0.004 & 0.2 & 0 & 0 \\
\hline Site(Location) & $5^{\mathrm{a}}$ & 1.190 & 55.1 & 0.840 & 55 \\
\hline Residual & 16 & 0.967 & 44.7 & 0.688 & 45 \\
\hline \multicolumn{6}{|c|}{ H. erythrogramma } \\
\hline Location & 2 & 0.089 & 3.3 & 0 & 0 \\
\hline Site(Location) & 6 & 1.602 & 59.1 & 1.343 & 62.7 \\
\hline Residual & 18 & 1.020 & 37.6 & 0.798 & 37.3 \\
\hline
\end{tabular}

Table 6. Nested 2-factor permutational multivariate analysis of variance (PERMANOVA) based on Euclidean distance matrix of fatty acid profiles for Jasus edwardsii (lobster), Haliotis rubra (abalone) and Ecklonia radiata (brown alga) individuals sampled from different locations within the Maria Island region and at sites nested within locations. Also shown are the pseudo-estimated variance component and the percentage variance for each term

\begin{tabular}{|lrrccrr|}
\hline Source & df & MS & \multicolumn{1}{c}{$F$} & $\mathrm{p}$ & Pseudo $\sigma$ & $\%$ \\
\hline J. edwardsii & & & & & & \\
Location & 2 & 63.811 & 1.830 & 0.124 & 3.22 & 11.6 \\
$\begin{array}{l}\text { Site(Location) } \\
\text { Residual }\end{array}$ & 6 & 34.870 & 1.791 & 0.054 & 5.13 & 18.5 \\
H. rubra & 18 & 19.467 & & & 19.47 & 70.0 \\
Location & 2 & 33.207 & 2.127 & 0.03 & 1.96 & 16.7 \\
Site(Location) & 6 & 15.612 & 2.282 & 0.003 & 2.92 & 24.9 \\
Residual & 18 & 6.841 & & & 6.84 & 58.4 \\
E. radiata & & & & & & \\
Location & 2 & 307.436 & 4.800 & 0.003 & 27.04 & 31.9 \\
Site(Location) & 6 & 64.050 & 1.176 & 0.299 & 3.19 & 3.8 \\
Residual & 18 & 54.476 & & & 54.48 & 64.3 \\
& & & & & & \\
\hline
\end{tabular}

0.05) explaining little of the overall variance. However, for Haliotis rubra and Ecklonia radiata, spatial terms did explain significant amounts of variance $(\mathrm{p}<0.05)$, but still the proportion of variance unexplained by these terms (and thus by the residual) remained high $(>58 \%)$.

\section{Intra-algal differences (within-plant scale)}

The most variable algal species in terms of intraalgal differences was Phyllospora comosa, whilst the least variable species was Durvillaea potatorum (Table 7, Fig. 6). The $\delta^{13} \mathrm{C}$ and $\delta^{15} \mathrm{~N}$ signatures of $D$. potatorum did not vary significantly between the stipe, mid-stem, mid- and upper blade and apex. In contrast, $P$. comosa fronds (mean $=10.1 \pm 0.4 \%$ ) were more enriched in $\delta^{15} \mathrm{~N}$ than the bladders (mean $=8.5 \pm 0.5 \%$ ) and stipes (mean $=9.0 \pm 0.5 \%$ ), and the fronds (mean $=$ $-17.2 \pm 1.0 \%$ ) were more enriched in $\delta^{13} \mathrm{C}$ than the stipes (mean $=-20.2 \pm 0.4 \%$; Tukey HSD post hoc test, Table 7 ). The $\delta^{13} \mathrm{C}$ and $\delta^{15} \mathrm{~N}$ signatures also varied between plant parts for Ecklonia radiata. The upper

Table 7. Durvillea potatorum, Ecklonia radiata and Phyllospora comosa. Summary of randomised block analysis of variance testing for differences in $\delta^{13} \mathrm{C}$ and $\delta^{15} \mathrm{~N}$ signatures between different parts of the algae. Tukey HSD post hoc tests indicate where algal parts differed. U.: upper; L.: lower

\begin{tabular}{|c|c|c|c|c|c|}
\hline Source & df & MS & $F$ ratio & $\mathrm{p}$ & Post hoc tests \\
\hline \multicolumn{6}{|l|}{$\begin{array}{l}\text { D. potatorum } \\
\delta^{13} \mathrm{C}\end{array}$} \\
\hline Plant part & 4 & 0.435 & 0.15 & 0.959 & \\
\hline Block (alga) & 3 & 12.736 & 4.409 & 0.026 & \\
\hline $\begin{array}{l}\text { Residual } \\
\delta^{15} \mathrm{~N}\end{array}$ & 12 & 2.889 & & & \\
\hline Plant part & 4 & 1.188 & 2.216 & 0.128 & \\
\hline Block (alga) & 3 & 1.753 & 3.27 & 0.059 & \\
\hline Residual & 12 & 0.536 & & & \\
\hline \multicolumn{6}{|l|}{$\begin{array}{l}\text { E. radiata } \\
\delta^{13} \mathrm{C}\end{array}$} \\
\hline Plant part & 5 & 2.292 & 2.807 & 0.029 & U. frond 1>Stipe \\
\hline Block (alga) & 8 & 15.396 & 18.855 & $<0.001$ & $(p=0.015)$ \\
\hline $\begin{array}{l}\text { Residual } \\
\delta^{15} \mathrm{~N}\end{array}$ & 40 & 0.817 & & & \\
\hline Plant part & 5 & 5.835 & 3.995 & 0.005 & L. frond >Stipe \\
\hline Block (alga) & 8 & 0.313 & 0.214 & 0.987 & $(p=0.03),>$ Apex \\
\hline Residual & 40 & 1.46 & & & $(p=0.004)$ \\
\hline \multicolumn{6}{|l|}{$\begin{array}{l}\text { P. comosa } \\
\delta^{13} \mathrm{C}\end{array}$} \\
\hline Plant part & 2 & 19.953 & 4.578 & 0.028 & Frond $>$ Stipe \\
\hline Block (alga) & 8 & 6.408 & 1.47 & 0.248 & $(p=0.031)$ \\
\hline $\begin{array}{l}\text { Residual } \\
\delta^{15} \mathrm{~N}\end{array}$ & 15 & 4.358 & & & \\
\hline Plant part & 2 & 6.342 & 7.325 & 0.006 & Frond>Bladder \\
\hline Block (alga) & 8 & 3.248 & 3.751 & 0.013 & $(p=0.006),>$ Stipe \\
\hline Residual & 15 & 0.866 & & & $(p=0.047)$ \\
\hline
\end{tabular}



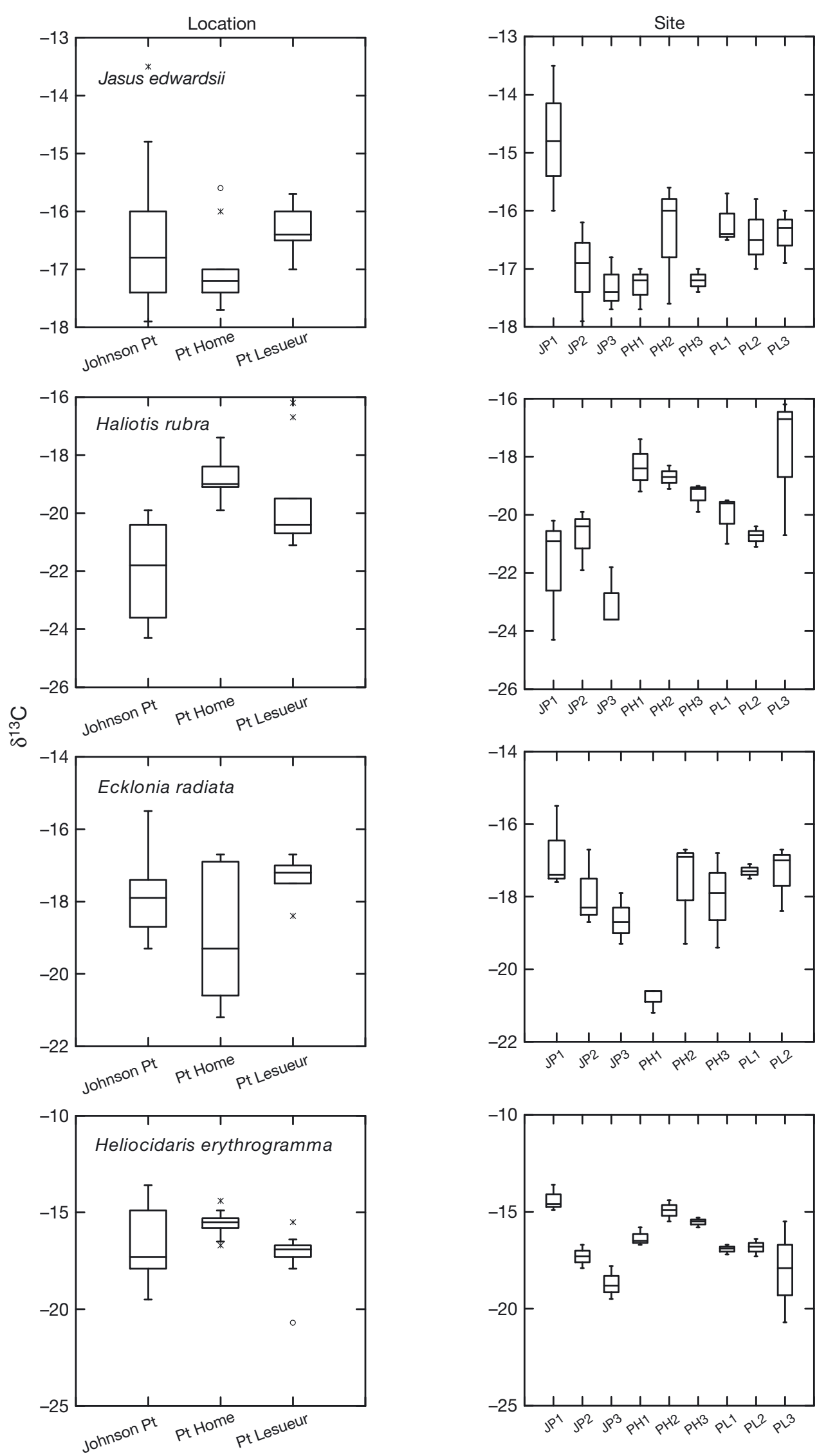

Fig. 4. $\delta^{13} \mathrm{C}$ ratios, displaying variance at location and site (nested with location) spatial scales for Jasus edwardsii (lobster), Haliotis rubra (abalone), Ecklonia radiata (brown alga) and Heliocidaris erythrogramma (urchin) at Maria Island. Horizontal lines are medians, boxes are inter-quartile ranges, and vertical bars are ranges excluding outliers $(*=$ outlier, $\circ=$ far outlier $)$ 

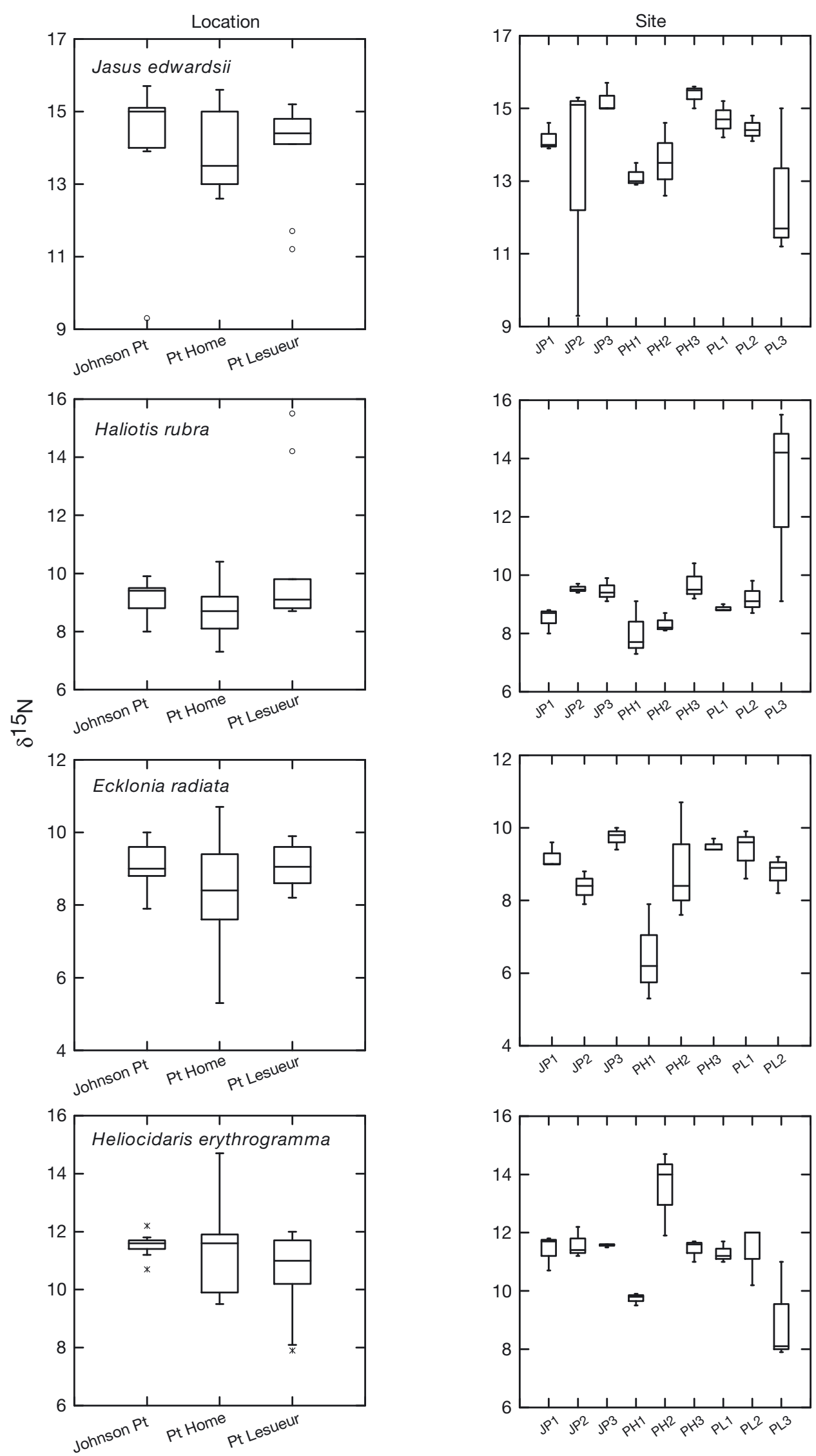

Fig. 5. $\delta^{15} \mathrm{~N}$ ratios. Other details as in Fig. 4 

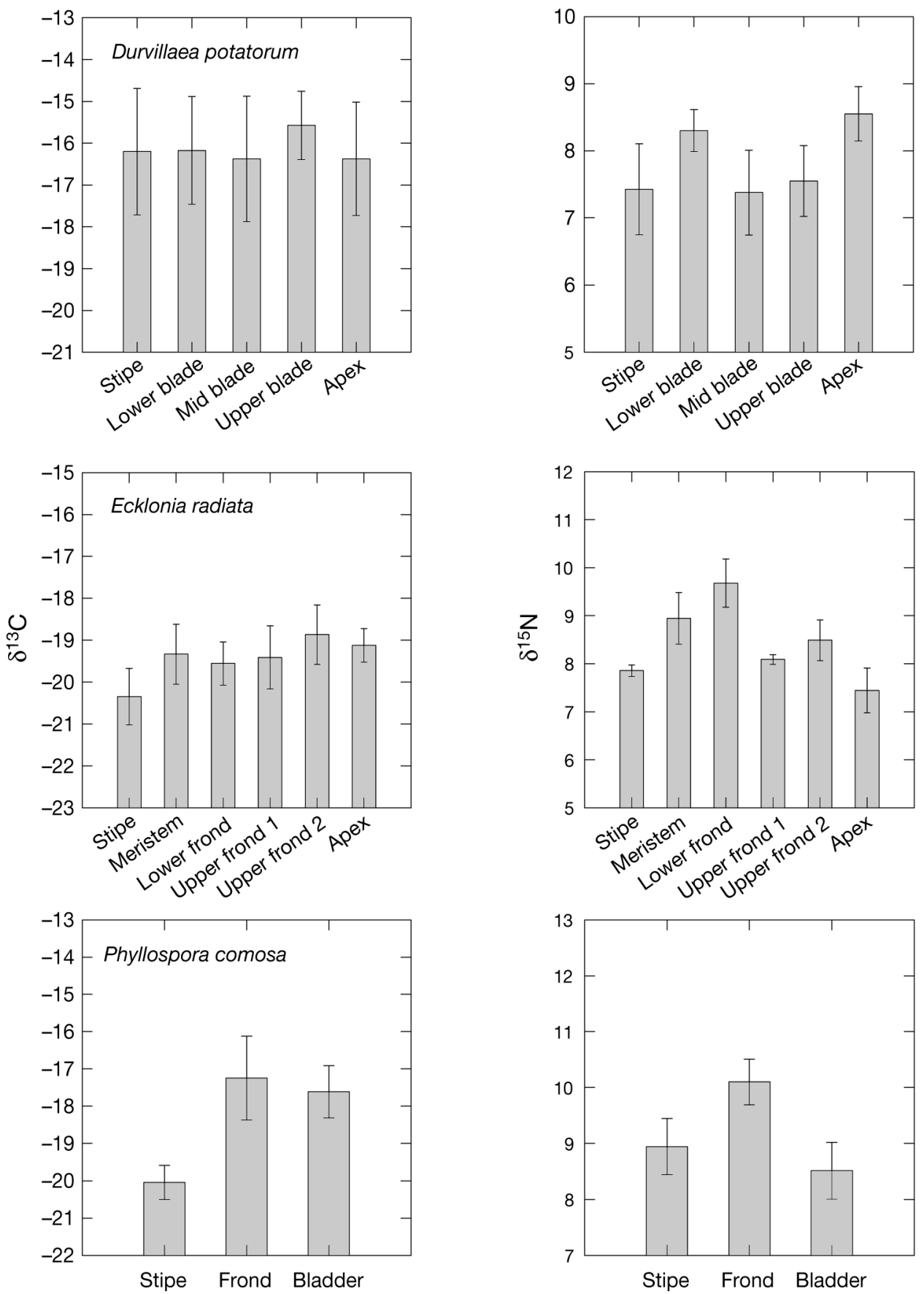

Fig. 6. Durvillaea potatorum, Ecklonia radiata and Phyllospora comosa. Mean $( \pm \mathrm{SE}) \delta^{13} \mathrm{C}$ and $\delta^{15} \mathrm{~N}$ stable isotope ratios of different plant parts

frond (mean $=-19.4 \pm 0.7 \%$ ) was more enriched in $\delta^{13} \mathrm{C}$ than the stipe (mean $=-20.3 \pm 0.6 \%$ ), although this difference was $<1 \%$ (Table 7 ). The lower frond of E. radiata (mean $=9.7 \pm 0.5 \%$ ) was also more enriched in $\delta^{15} \mathrm{~N}$ than the stipe (mean $=7.9 \pm 0.1 \%$ ) and the apex (mean $=7.4 \pm 0.4 \%$ ).

\section{DISCUSSION}

\section{At what spatial scales do biochemical tracers vary?}

This study is the first to explicitly partition (1) fatty acid profiles into their constituent spatial components, 
and (2) fatty acid profiles in combination with stable isotope ratios for the same organisms at multiple spatial scales. Stable isotope and fatty acid profiles were found to vary at different spatial scales. The greatest amount of variation for stable isotopes was recorded at the intermediate spatial scale (i.e. 100 to $1000 \mathrm{~m}$ scale), whereas fatty acid profiles varied most between replicate samples. Whilst this pattern of tracer variation appeared to be generally consistent within a species across scales for stable isotopes and fatty acids (i.e. regional and meso-scales), the pattern did vary between species, such that invertebrate and macroalgal fatty acid profiles displayed differing patterns of variance across the spatial scales considered (Table 3).

One of the most interesting findings of this study was that biochemical tracers were least variable at the largest spatial scales considered. Where regional patterns were observed, the differences were not as anticipated. For example, the most isolated coastline sampled, the west coast, could rarely be distinguished from the other regions (with the exception of $\delta^{13} \mathrm{C}$ ratios for Ecklonia radiata). In comparison to the east and southeast coasts of Tasmania, the west coast is largely unpopulated and is exposed to heavy oceanic swell from the Southern Ocean (falling within the latitudes of the 'Roaring 40s'). Whereas the east coast of Tasmania is primarily influenced by the southward flowing East Australian Current (EAC) in summer, the west coast is influenced by the weaker Zeehan Current and receives freshwater and terrigenous input from a number of major river systems. This finding implies that broadscale processes in Tasmania can be characterised without the need to sample intensively at this larger, regional scale.

Intra-plant variation in carbon and nitrogen stable isotope signatures was also detected in this study, notably for the alga Phyllospora comosa, but was not consistent between species or elements. Intra-plant variability in $\delta^{15} \mathrm{~N}$ and $\delta^{13} \mathrm{C}$ is attributed to the source, storage and metabolism of plant nitrogen and/or carbon (Schmitz \& Loban 1976, Vizzini \& Mazzola 2003). Understanding intra-plant variability in stable isotope signatures of autotrophs provides a useful guide of how to process autotrophs for trophic studies. No differences were found for $\delta^{13} \mathrm{C}$ and $\delta^{15} \mathrm{~N}$ for Durvillaea potatorum and $\delta^{13} \mathrm{C}$ signatures for Ecklonia radiata. For these algal species, small sections of the alga may be considered to represent the entire plant, and for large cumbersome algae such as D. potatorum, thus will reduce the difficulty associated with the transport and storage of whole-alga samples. By contrast, the $\delta^{15} \mathrm{~N}$ of E. radiata and both $\delta^{13} \mathrm{C}$ and $\delta^{15} \mathrm{~N}$ signatures of $P$. Comosa varied significantly between plant parts. Consequently, it is difficult to provide general advice about the variability of algal plant structures. Addition- ally, as the part of the plant that is eaten directly by the consumer is often unknown, or contributes to the diet of the consumer via the detrital pathway (e.g. Jaramillo et al. 2003, Guest et al. 2004, Tala \& Edding 2005, Decottignies et al. 2007), a composite sample that provides an average isotope signature of the autotroph is recommended.

Intra-plant variability of carbon isotopes has previously been reported for macroalgae. The distal parts of Ecklonia radiata (Fenton \& Ritz 1989) and Laminaria longicruris (Stephenson et al. 1984) were more depleted (i.e. more negative) in $\delta^{13} \mathrm{C}$ (by $\sim 3-7 \%$ and $2.1-8 \%$, respectively) than the remainder of the plant. No such pattern was recorded for parts of E. radiata in the current study. The $\delta^{13} \mathrm{C}$ signatures of all algal parts in the current study were also generally more negative (mean $\pm \mathrm{SE}=-19.4 \pm 0.2 \%$ ) than that reported for $E$. radiata previously (mean $=-16.1 \pm 0.2 \%$, Fenton \& Ritz 1989), suggesting that other factors such as the size/age of the algal fronds (e.g. Stephenson et al. 1984) or the time of collection may provide a better explanation for the observed homogeneity of isotope signatures. No previous studies have examined the intra-plant variability of $\delta^{15} \mathrm{~N}$ signatures in macroalgae. For the seagrass Posidonia oceanica, rhizomes were more enriched in $\delta^{15} \mathrm{~N}$ than leaves, leaf litter and aegragrophiles in all seasons except in spring, where there was no difference between $\delta^{15} \mathrm{~N}$ signatures of rhizomes and leaf litter (Vizzini \& Mazzola 2003).

\section{Implications of spatial variation amongst chemical tracers for the design of trophic studies using biochemical tracers}

Ecologists have long been aware that spatial variability has important implications for the design, and subsequent analysis, of experiments and surveys (Morrisey et al. 1992, Downes et al. 1993, Underwood \& Petraitis 1993). This is because the results of experiments depend critically upon the spatial scale at which they are undertaken. Where the scale of sampling is incongruous with the hypotheses proposed, spatial variation may confound conclusions, making logical interpretation impossible (Underwood 1997). Moreover, where scales of spatial variability are poorly understood, incorrect allocation of sampling effort may act to decrease the probability of detecting differences between samples and treatments (i.e. influence the power of statistical tests).

The potential for spatial variability in stable isotope signatures to confound interpretation of trophic studies was first illustrated by Simenstad et al.'s (1993) study of organic matter derived from kelp production in the Aleutian Islands, Alaska. Simenstad et al. (1993) found 
that $\delta^{13} \mathrm{C}$ signatures were more variable between sites (i.e. locations separated by 100 s of metres and nested within islands) than islands (separated by $10 \mathrm{~s}$ of $\mathrm{km}$ ). Such variability may confound interpretation where only a single site or small number of sites are used to characterise the stable isotope signature of islands at the scale of the entire Aleutian island system. Similarly, Jennings et al. (1997) found that high variability in $\delta^{13} \mathrm{C}$ signatures between sites for a range of reef species obscured attempts to determine the importance of alternate trophic pathways. In the current study, we also detected significant and high variation for stable isotope signatures at the level of sites relative to the broader regional and the smaller replicate sample (i.e. residual term) scales sampled. Failure to incorporate sufficient sampling at this smaller spatial scale may therefore hinder attempts to adequately characterise and understand trophic patterns at larger geographic spatial scales.

In contrast to stable isotopes, little is known about the spatial scales at which fatty acid chemical tracers vary. Currently, there is limited information upon which to base the allocation of sampling effort across a range of spatial scales pertinent to the trophic questions studied. Moreover, when used in conjunction with other chemical tracers, such as stable isotopes, it is currently not possible to know whether the design used for one chemical tracer is also appropriate for another. In the current study, spatial variation in fatty acid profiles for all taxa was generally greatest among individual replicate samples irrespective of the spatial scale examined. This finding implies that high sample variability is a potential source of confounding where insufficient replicates are used to characterise the fatty acid profiles of target species. As consequence, future application of fatty acid profiles to examine trophic relationships should maximise replication among individuals within treatments to determine dietary relationships.

The results of this study suggest that broadscale comparisons are likely to be confounded by insufficient sampling at smaller spatial scales. This is evident in the variation in stable isotope signatures that was greatest between sites (and to a lesser extent between samples), whereas variation in fatty acid profiles was greatest between replicate samples. In the case of fatty acid profiles of consumers such as abalone and rock lobster, residual variance accounted for the majority of the variance expressed (>60\%). In trophic surveys, high variation in chemical tracers at small to intermediate spatial scales may lead to the incorrect attribution of a food source to a consumer's diet, and/or incorrect assignation of trophic status. For example, shifts of $\sim 3 \%$ in $\delta^{15} \mathrm{~N}$ (e.g. Minagawa \& Wada 1984, McCutchan et al. 2003) between a producer and each higher trophic level are considered to reflect the trophic status of a consumer. Variation in $\delta^{15} \mathrm{~N}$ that is due to the spatial scale of sampling may therefore lead to incorrect assignation of trophic status. Similarly, high variability among replicate samples in fatty acid profiles, or insufficient replication among individuals may hinder the clarification of trophic relationships at larger spatial scales. We emphasise that appropriate allocation of effort does not necessarily mean increasing the number of replicates across the design, but that replicates are correctly assigned to the scale at which most variability occurs to better characterise that variation in biochemical tracers in order to avoid erroneous conclusions.

\section{Scales of variability: causal mechanisms}

Biochemical tracer signatures of consumers may be influenced by the age, size and sex of an individual (i.e. for fatty acids, those characteristics that influence consumer behaviour and/or metabolism, thus altering consumer fatty acid profiles). In the current study, there was no relationship between consumer size and fatty acid profile, although this may be due to the homogeneous size distribution of the populations sampled. The diverse diets of lobsters and wrasses may partly explain the high variability in fatty acid profiles among individuals even of the same size class. Moult or reproductive stage may also influence lobster fatty acid profiles (Ritar et al. 2003). Where possible, it would be advantageous to standardise factors such as the size, sex and moult stage of individuals to reduce variability between samples.

Small-scale spatial variation can often be misconstrued for temporal change between sampling events if the variance at these 2 scales is not explicitly and carefully partitioned in the sampling design (Thrush et al. 1996, Underwood 1997). Such variation, due to small-scale patchiness and spatial heterogeneity, may often exceed temporal variation in marine systems (Hirst \& Kilpatrick 2007) and is a common source of experimental confounding in field studies. Alternately, as environmental and physiological factors may change over time/season, temporal variation in biochemical profiles may be interpreted as spatial variation where spatial and temporal variation are not considered explicitly. In the current study, the potential influence of temporal variability was minimised by sampling all spatial scales within a 3 mo period (and for most, within a 2 mo period) during winter months that displayed colder water temperatures and slower growth rates, thus reducing the likelihood of rapid physiological and/or environmental change across the period considered. 
Nested sampling designs may also provide important clues about the scale at which ecological processes operate (Underwood 1997), by allowing identification of the spatial scales at which chemical tracers vary. In this study, stable isotope signatures were found to vary principally between sites (and to a lesser extent between samples), whereas fatty acid profiles varied primarily between replicate samples and, depending on the species examined, to a lesser degree between sites. This finding supports the notion that $\delta^{13} \mathrm{C}$ and $\delta^{15} \mathrm{~N}$ stable isotope signature variation is primarily influenced by environmental factors and secondarily by metabolism. By contrast, fatty acid profiles may primarily be influenced by metabolism and secondarily by environmental factors. Metabolism is influenced by food availability and quality, growth rate, the reproductive stage of the organism and the functional role of the tissues analysed (Chandrapavan et al. 2009). Such insights allow us both to allocate sampling effort accordingly for future survey designs, but also allow explicit hypothesis testing of the potential causes of tracer variability in experimental studies, thereby improving the application of biochemical tracers to understanding dietary relationships.

\section{CONCLUSIONS}

This study is one of the first to explicitly partition spatial variance for chemical tracers and the first to examine spatial variance simultaneously for stable isotopes and fatty acids. Stable isotopes varied principally between sites nested within locations sampled at broader spatial scales. In comparison, fatty acid profiles varied principally between replicate samples nested within sites. In general, little variance was expressed in fatty acid profiles at the broad geographic scale in comparison to the smaller scales sampled. The differing spatial variance structure for stable isotopes and fatty acids may suggest that these chemical tracers are influenced to a varying degree by factors that operate at different spatial scales (i.e. environmental versus physiological factors). However, these differences may potentially strengthen their application when used in combination because they allow studies to measure alternate aspects of food web structure. The results indicate that sampling designs that are tailored for one chemical tracer may not necessarily be suitable for another. Our results indicate that whilst sampling at the scale of sites is important when using stable isotopes, greater emphasis should be placed on collecting more individual replicate samples when using fatty acid techniques. In most cases, this can be achieved by allocating differing levels of sampling intensity for different chemical tracers within the overall design, with- out compromising the sensitivity of the design. The results of this study also clearly indicate that failure to undertake replicate sampling at smaller to intermediate spatial scales may lead to potentially confounded interpretations about patterns at broader spatial scales.

Acknowledgements. We thank B. Connell, S. Fava, S. Ibbott and R. Kilpatrick for assistance in the field. The assistance of B. Mooney with laboratory processing and interpretation of fatty acid profiles was especially helpful. D. Holdsworth managed the CSIRO GC-MS facility. Thanks to M. Morffew for creating the map.

\section{LITERATURE CITED}

Alcoverro T, Cerbian E, Ballesteros E (2001) The photosynthetic capacity of the seagrass Posidonia oceanica: influence of nitrogen and light. J Exp Mar Biol Ecol 261: $107-120$

> Alfaro AC, Thomas F, Sergent L, Duxbury M (2006) Identification of trophic interactions within an estuarine food web (northern New Zealand) using fatty acid biomarkers and stable isotopes. Estuar Coast Shelf Sci 70:271-286

Anderson MJ (2005) PERMANOVA: a FORTRAN computer program for permutational multivariate analysis of variance. Department of Statistics, University of Auckland

> Anderson MJ, Connell SD, Gillanders BM, Diebel CE, Blom WM, Saunders JE, Landers TJ (2005) Relationships between taxonomic resolution and spatial scales of multivariate variation. J Anim Ecol 74:636-646

Andrews JE, Greenaway AM, Dennis PF (1998) Combined carbon isotope and $\mathrm{C} / \mathrm{N}$ ratios as indicators of source and fate of organic matter in a poorly flushed, tropical estuary: Hunts Bay, Kingston Harbour, Jamaica. Estuar Coast Shelf Sci 46:743-756

$>$ Boon PI, Bunn SE (1994) Variations in the stable isotope composition of aquatic plants and their implications for food web analysis. Aquat Bot 48:99-108

> Boyce MC, Lavery P, Bennett IJ, Horwitz P (2001) Spatial variation in the $\delta^{13} \mathrm{C}$ signature of Ruppia megacarpa (Mason) in coastal lagoons of southwestern Australia and its implication for isotopic studies. Aquat Bot 71:83-92

Burkhardt S, Riebessell U, Zondervan I (1999) Stable carbon isotope fractionation by marine phytoplankton in response to daylength, growth rate and $\mathrm{CO}_{2}$ availability. Mar Ecol Prog Ser 184:31-41

Chandrapavan A, Guest MA, Nichols PD, Gardner C (2009) Translocating southern rock lobsters (Jasus edwardsii) from deep-water to shallow inshore water enhances nutritional condition through omega-3 long-chain polyunsaturated fatty acid content. J Exp Mar Biol Ecol 375:9-15

Christie WW (1982) Lipid analysis. Pergamon Press, Oxford

Corraze G (1999) Lipid nutrition. In: Guillaume J, Metailler R, Kaushik S, Bergot P (eds) Nutrition and feeding of fish and crustaceans. Springer, London, p 111-130

Dalsgaard J, St. John M, Kattner G, Müller-Navarra D, Hagen W (2003) Fatty acid trophic markers in the pelagic marine environment. Adv Mar Biol 46:225-340

> Decottignies P, Beninger PG, Rince Y, Robins RJ, Riera P (2007) Exploitation of natural food sources by two sympatric, invasive suspension-feeders: Crassostrea gigas and Crepidula fornicata. Mar Ecol Prog Ser 334:179-192

> Deegan LA, Garritt RH (1997) Evidence for spatial variability in estuarine food webs. Mar Ecol Prog Ser 147:31-47

Denny CM, Schiel CR (2001) Feeding ecology of the banded 
wrasse Notolabrus fucicola (Labridae) in southern New Zealand: prey items, seasonal differences, and ontogenetic variation. N Z J Mar Freshw Res 35:925-933

Dittmar T, Lara RJ, Kattner G (2001) River or mangrove? Tracing major organic matter sources in tropical Brazilian coastal waters. Mar Chem 73:253-271

> Downes BJ, Lake PS, Schreiber ESG (1993) Spatial variation in the distribution of stream invertebrates: implications of patchiness for models of community organization. Freshw Biol 30:119-132

Edgar GJ, Moverley JH, Barrett NS, Peters D, Reed C (1997) The conservation-related benefits of a systematic marine biological sampling programme: the Tasmanian reef bioregionalisation as a case study. Biol Conserv 79: 227-240

Fenton GE, Ritz DA (1989) Spatial variability of ${ }^{13} \mathrm{C}:{ }^{12} \mathrm{C}$ and D:H in Ecklonia radiata (C.Ag.) J. Agardh (Laminariales). Estuar Coast Shelf Sci 28:95-102

Finlay JC (2004) Patterns and controls of lotic algal stable carbon isotope ratios. Limnol Oceanogr 49:850-861

> Grice AM, Loneragan NR, Dennison WC (1996) Light intensity and the interactions between physiology, morphology and stable isotope ratios in five species of seagrass. J Exp Mar Biol Ecol 195:91-110

> Guest MA, Connolly RM, Loneragan NR (2004) Within and among-site variability in $\delta^{13} \mathrm{C}$ and $\delta^{15} \mathrm{~N}$ for three estuarine producers, Sporobolus virginicus, Zostera capricorni, and epiphytes of Z. capricorni. Aquat Bot 79:87-94

> Guest MA, Nichols PD, Frusher SD, Hirst AJ (2008) Evidence of abalone (Haliotis rubra) diet from combined fatty acid and stable isotope analyses. Mar Biol 153:579-588

> Guest MA, Frusher SD, Nichols PD, Johnson CR, Wheatley KE (2009) The trophic effects of fishing southern rock lobster (Jasus edwardsii) shown by combined fatty acid and stable isotope analyses. Mar Ecol Prog Ser 388:169-184

> Hemminga MA, Mateo MA (1996) Stable carbon isotopes in seagrasses: variability in ratios and use in ecological studies. Mar Ecol Prog Ser 140:285-298

Hirst AJ, Kilpatrick R (2007) Spatial and temporal variation in the structure of estuarine macroinvertebrate assemblages: implications for assessing the health of estuaries. Mar Freshw Res 58:866-879

> Iverson SJ, Frost KK, Lowry LL (1997) Fatty acid signatures reveal fine scale structure of foraging distribution of harbor seals and their prey in Prince William Sound, Alaska. Mar Ecol Prog Ser 151:255-271

Iverson SJ, Springer AM, Kitaysky AS (2007) Seabirds as indicators of food web structure and ecosystem variability: qualitative and quantitative diet analyses using fatty acids. Mar Ecol Prog Ser 352:235-244

Jack L, Wing SR, McLeod RJ (2009) Prey base shifts in red rock lobster Jasus edwardsii in response to habitat conversion in Fiordland marine reserves: implications for effective spatial management. Mar Ecol Prog Ser 381:213-222

> Jaramillo E, Contreras H, Duarte C, Avellanal MH (2003) Locomotor activity and zonation of upper shore arthropods in a sandy beach of north central Chile. Estuar Coast Shelf Sci 58:177-197

> Jaschinski S, Brepohl DC, Sommer U (2008) Carbon sources and trophic structure in an eelgrass Zostera marina bed, based on stable isotope and fatty acid analyses. Mar Ecol Prog Ser 358:103-114

Jennings S, Renones O, Morales-Nin B, Polunin NVC, Moranta J, Coll J (1997) Spatial variation in the ${ }^{15} \mathrm{~N}$ and ${ }^{13} \mathrm{C}$ stable isotope composition of plants, invertebrates and fishes on Mediterranean reefs: implications for the study of trophic pathways. Mar Ecol Prog Ser 146:109-116
Kharlamenko VI, Kiyashko SI, Imbs AB, Vyshkvartzev DI (2001) Identification of food sources of invertebrates from the seagrass Zostera marina community using carbon and sulfur stable isotope ratio and fatty acid analyses. Mar Ecol Prog Ser 220:103-117

- Lewis T, Nichols PD, McMeekin TA (2000) Evaluation of extraction methods for recovery of fatty acids from lipidproducing microheterotrophs. J Microbiol Methods 43: $107-116$

Marguillier S, van der Velde G, Dehairs F, Hemminga MA, Rajagopal S (1997) Trophic relationships in an interlinked mangrove-seagrass ecosystem as traced by $\delta^{13} \mathrm{C}$ and $\delta^{15} \mathrm{~N}$. Mar Ecol Prog Ser 151:115?121

> McArdle BH, Anderson MJ (2001) Fitting multivariate models to community data: a comment on distance-based redundancy analysis. Ecology 82:290?297

McCutchan JH, Lewis WM, Kendall C, McGrath CC (2003) Variation in trophic shift for stable isotope ratios of carbon, nitrogen, and sulfur. Oikos 102:378-390

Minagawa M, Wada E (1984) Stepwise enrichment of ${ }^{15} \mathrm{~N}$ along food chains. Further evidence and the relation between $\delta^{15} \mathrm{~N}$ and animal age. Geochim Cosmochim Acta 48:1135-1140

> Morrisey DJ, Howitt L, Underwood AJ, Stark JS (1992) Spatial variation in soft-sediment benthos. Mar Ecol Prog Ser 81: $197-204$

Odum EP, Fisher JS, Pickrel JC (1979) Factors controlling the flux of particulate organic carbon from estuarine wetlands. In: Livingston EJ (ed) Ecological processes in coastal and marine systems. Plenum Press, New York, NY, p 69-79

Peterson BJ (1999) Stable isotopes as tracers of organic matter input and transfer in benthic food webs: a review. Acta Oecol 20:479-487

Peterson BJ, Fry B (1987) Stable isotopes in ecosystem studies. Annu Rev Ecol Syst 18:293-320

Phillips KL, Nichols PD, Jackson GD (2003a) Size-related changes observed in the squid Moroteuthis ingens at the Falkland Islands: stomach contents and fatty acid analyses. Polar Biol 26:474-485

> Phillips KL, Nichols PD, Jackson GD (2003b) Temporal variations in the diet of the squid Moroteuthis ingens at Macquarie Island: stomach contents and fatty acid analyses. Mar Ecol Prog Ser 256:135-149

Ritar AJ, Dunstan GA, Crear BJ, Brown MR (2003) Biochemical composition during growth and starvation of early larval stages of cultured spiny lobster (Jasus edwardsii) phyllosoma. Comp Biochem Physiol A Mol Integr Physiol 136: 353-370

Sanderson CJ, Rossignol M, James W (1996) A pilot program to maximise Tasmania's sea urchin (Heliocidaris erythrogramma) resource. Final report to the Fisheries Research and Development Corporation, Australia, FRDC 93/221

> Schmitz K, Loban CS (1976) A survey of translocation in Laminariales (Phaeophyceae). Mar Biol 36:207-216

Searle SR, Casella G, McCulloch CE (1992) Variance components. Wiley Press, New York, NY

Simenstad CA, Duggins DO, Quay PD (1993) High turnover of inorganic carbon in kelp habitats as a cause of $\delta^{13} \mathrm{C}$ variability in marine food webs. Mar Biol 116:147-160

Soreide JE, Falk-Petersen S, Hegseth EN, Hop H, Carroll ML, Hobson KA, Blachowiak-Samolyk K (2008) Seasonal feeding strategies of Calanus in the high-Arctic Svalbard region. Deep-Sea Res II 55:2225-2244

Steneck RS, Graham MH, Bourque BJ, Corbett D, Erlandson JM, Estes JA, Tegner MJ (2002) Kelp forest ecosystems: biodiversity, stability, resilience and future. Environ Con- 
serv 29:436-459

Stephenson RL, Tan FC, Mann KH (1984) Stable carbon isotope variability in marine macrophytes and its implications for food web studies. Mar Biol 81:223-230

Stevens CJ, Limen H, Pond DW, Gelinas Y, Juniper SK (2008) Ontogenetic shifts in the trophic ecology of two alvinocaridid shrimp species at hydrothermal vents on the Mariana Arc, western Pacific Ocean. Mar Ecol Prog Ser 356: 225-237

Tala F, Edding M (2005) Growth and loss of distal tissue in blades of Lessonia nigrescens and Lessonia trabeculata (Laminariales). Aquat Bot 82:39-54

Thrush SF, Pridmore RD, Hewitt JE (1996) Impacts on softsediment macrofauna. The effects of spatial variation on temporal trends. In: Schmitt RJ, Osenberg CW (eds) Detecting ecological impacts: concepts and applications in coastal habitats. Academic Press, San Diego, CA, p 49-66

Tucker S, Bowen WD, Iverson SJ (2008) Convergence of diet estimates derived from fatty acids and stable isotopes

Editorial responsibility: Matthias Seaman,

Oldendorf/Luhe, Germany within individual grey seals. Mar Ecol Prog Ser 354: $267-276$

Underwood AJ (1997) Experiments in ecology: their logical design and interpretation using analysis of variance. Cambridge University Press, Cambridge

Underwood AJ, Petraitis PS (1993) Structure of intertidal assemblages in different locations: How can local processes be compared? In: Ricklefs RE, Schluter D (eds) Species diversity in ecological communities: historical and geographical perspectives. University of Chicago Press, Chicago, IL, p 38-51

Vizzini S, Mazzola A (2003) Seasonal variations in the stable carbon and nitrogen isotope ratios $\left({ }^{13} \mathrm{C} /{ }^{12} \mathrm{C}\right.$ and $\left.{ }^{15} \mathrm{~N} /{ }^{14} \mathrm{~N}\right)$ of primary producers and consumers in a western Mediterranean lagoon. Mar Biol 142:1009-1018

Waser NAD, Harrison PJ, Nielsen B, Calvert SE, Turpin DH (1998) Nitrogen isotope fractionation during the uptake and assimilation of nitrate, nitrite, ammonium, and urea by a marine diatom. Limnol Oceanogr 43:215-224

Submitted: August 18, 2008; Accepted: April 13, 2010 Proofs received from author(s): July 2, 2010 